\title{
СПОСОБЫ ПРАВОВОГО УЧЕТА ПЕРСОНАЛЬНЫХ ОСОБЕННОСТЕЙ СУБЪЕКТА ПРАВООТНОШЕНИЙ
}

\section{METHODS OF LEGAL ACCOUNTING FOR THE PERSONAL CHARACTERISTICS OF THE SUBJECT OF LEGAL RELATIONS}

N. Zaytseva

Summary. Legal relations, like any other relations in the social sphere, involve building connections between subjects of different content. A feature of relations in the field of law is the emergence of obligations, for the fulfillment of which, among other things, the force of state coercion can be used. Such consequences predetermine a different approach to considering the psychological characteristics of the subject of legal relations. The law knows several mechanisms and stages of checking the ability of a participant in a legal relationship to understand the nature of his actions and to associate his actions with the consequences. The purpose of this article is to study the methods of considering subjective characteristics and the legal significance of legal capacity in the formation of a legal connection.

Keywords: legal relationship, elements of legal connection, legal capacity, emancipation, individual characteristics.

\author{
Зайчева Наталья Викторовна \\ К.ю.н., доцент, Российская академия народного \\ хозяйства и государственной службы при \\ Президенте РФ \\ zaytsevanv@gmail.com
}

Аннотация. Правоотношения, как и любые другие отношения в социальной сфере предполагают выстраивание связей между субъектами различного содержания. Особенностью отношений в сфере права является возникновение обязательств, для исполнения которых в том числе может быть задействована сила государственного принуждения. Такие последствия предопределяют иной подход к учету психологических особенностей субъекта правоотношения. Право знает несколько механизмов и этапов проверки способности участника правоотношения осознавать характер своих действий и связывать свои действия с последствиями. Целью настоящей статьи является изучение способов учета субъективных особенностей и правовое значение дее - и правоспособности в формирование правовой связи.

Ключевые слова: правоотношение, элементы правовой связи, правоспособность, дееспособность, эмансипация, индивидуальные особенности.
Д октрина права исходит из парадигмы, что для построения юридического отношения нужны следующие элементы: участники, независимость и автономность, форма отражающая намерения, норма регулирующая отношение, права и обязанности участников, объект и причина нахождения в отношениях (цель преследуемая участниками). Некоторые ученые рассматривают правоотношение в развитии поэтому состав участников учитывает не только непосредственно стороны, но и тех, кто влияет на судьбу контракта - судьи, арбитры, нотариусы и т.д. Как отмечал Г. Павлакоса, две партии создают новую ситуацию, которая является своего рода третьей сущностью (две вместе - это больше, чем две партии по отдельности) [1]. Также и с правоотношением, две стороны создают правоотношение, которое получает иное содержание чем первоначальная воля и представление стороны по отдельности [2].

Другой элемент - это автономность, к который должны стремиться стороны в том числе в случае взаимозависимости. Правовые отношения - это справедливое расстояние между автономными сторонами и другими участниками, то есть пространство или разрыв, что исключает отношения без срока или без возможности выхода из него.

Специальная форма правоотношения существовала всегда, при этом часто она проходила через символизацию процесса возникновения правоотношения [3]. В настоящее время соглашения, составленные в письменной форме, заменили по сути любые действия, символизирующие создание договорных отношений.

Норма как элемент правоотношения подразумевает существование правила, которого в равной степени должны придерживаться участники [4]. В правоотношениях всегда есть процессуальный аспект, поскольку он развивается с течением времени. Этот стандарт установлен с учетом ценностей, в основном стремления к автономии, а также независимости третьей стороны, обладающей полномочиями. В теории права исторически сложилось два направления, которые определяют первичность возникновения права или нормы друг по отношению к другу [5]. Норма также может выходь за пределы правовых отношений и образовывать- 
ся в рамках других правоотношений. Часто правовой стандарт поведения создается извне - в отношениях, подлежащих интерпретации [6].

Правовые отношения всегда имеют цель: товары в договорных отношениях купли-продажи, услуга в соглашении по предоставлению услуги, образование в отношениях в сфере науки и образования, судебное разбирательство в процессуальных отношениях, государственная услуга в отношениях гражданства. Правовые отношения, связанные с объектом, исключенным из оборота, по общему правилу не имеют юридической силы.

Правоотношения также имеют причины, которые в отличие от цели могут быть законными и незаконными. Так, в некоторых юрисдикциях, фиктивный брак для получения вида на жительство может быть расторгнут, а не признается недействительным изначально. Правовые отношения - это динамический механизм с постоянными транзакциями, касающимися сторон, каждая из которых должна соответствовать критерию законности.

Любая теория права рассматривает правовое регулирование отношений с точки зрения источников, правового порядка и эффективности, также существенное различие возникает от разного пересечения закона и морали. В рамках данной темы исследования особого внимания заслуживает способ, с помощью которого субъект получает доступ к правовой информации, это могут быть ощущения, разум, эмоция или интуиция, все они подлежат квалификации при оценке поведения судом.

Большую роль в оценке поведения играет теория интерпретации норм, которая с одной стороны осуществляется сторонами, с другой стороны с помощью арбитра, наделенного полномочиями. Реляционизм способствует интерпретации нормы между самими сторонами с помощью третьей стороны, обладающей полномочиями. Тест Дж. Недельского [7] можно использовать для интерпретации нормы: какие правовые отношения задействованы, какие интересы и ценности задействованы, какая интерпретация максимизирует автономию сторон? В судебном процессе стороны находятся под эгидой судьи в соответствии с процедурными обязательствами. Судья связан с другими членами судебной системы процессуальными узами поскольку помещается в определенную должностную иерархию и следовательно, судья имеет правовые ограничения в своем толковании, которое зависит от его прав и обязанностей в процессуальных и судебных отношениях. Поэтому от пределов судебной дискреции и уровня правосознания отдельного арбитра или судьи будет за- висит правовое наполнение договорного положения, правового принципа и законодательной нормы.

Совокупность правовых отношений, можно рассматривать как правопорядок, при этом национальный правопорядок не является закрытым как по отношению к другим более общим порядкам (право союзных государств, международное право), так и к нормам, регулирующим отношения, выходящих за рамки правовых порядков (например, смешанные браки, группа транснациональных компаний, спортивные федерации и т.д.).

Различие между моралью и законом играет большое значение в части перспектив и эффективности правового регулирования таких вопросов, на которые в настоящий момент времени нет ответа (например введение эвтаназии или разрешение суррогатного материнства). Решение правовой судьбы таких историй может быть социальным или индивидуальным. Это становится законом, когда решение выбирается в рамках политических правовых отношений или когда оно является частью определенных правовых отношений (семейные и медицинские отношения). Однако мораль должна находиться в политической иерархии выше закона, поэтому любые политические решения несоответствующие морали должны быть признаны незаконными. Помимо морали, право объединяет эмоции, ощущения, разум и интуицию, при этом их учет не должен привести к психологизации правовых отношений. Например, процессуальное право с помощью создания специальных процедур направлено на сдерживание эмоциональной составляющей, что должно помогать в выработке судебного решения.

С субъективной составляющей и возможностью ее учета тесно связана правовая эффективность, поскольку с одной стороны только учет действительных намерений сторон приведет к желаемому результату и обеспечит больше доверие к праву в целом, с другой стороны правовые стандарты должны одинаково восприниматься и толковаться теми, кому правовая норма адресована.

Рассматривая с правовой точки зрения субъекта, нельзя не отметить, следующее. Учет всех психологических особенностей индивида в рамках правового регулирования и практики применения - невозможен. Задача права в каком-то смысле - находить общее в правовых и социальных связях и через обобщенные категории, понятия и критерии регулировать частное. Там, где учет персональных особенностей критичен, законодатель наделяет государственных агентов максимально большими ресурсами, которые позволяют каждый раз определять индивидуальные характеристики. 
Однако в большинстве частных отношений законодатель, наоборот, пытается избежать излишней персонализации процесса, поэтому идет по пути упрощения и усреднения.

Первым таким проявлением юридического обобщения на нормативном уровне является понятие дееспособности и правоспособности. Определение, используемое в Гражданском кодексе РФ для правовой идентификации правоспособности звучит как «способность иметь права и нести обязанности» (Статья 17 ГК РФ https://www.consultant.ru/document/ cons_doc_LAW_5142/), а дееспособность «как способность своими действиями приобретать и осуществлять гражданские права, создавать для себя гражданские обязанности и исполнять их» (Статья 21 ГК РФ https:// www.consultant.ru/document/cons_doc_LAW_5142/.) Несмотря на незначительную разницу в формулировках, законодатель в случае с правоспособностью отказывается от учета субъективной составляющей поскольку правоспособность, как категория предполагает пассивность субъектов в его способности иметь права[8]. Перенос акцента с пассивного состояния на активные действия ставит вопрос об оценке психологических характеристик присущих субъекту. Следует отметить, что доктрина не пришла к единому выводу, какой фактор критичен при оценке действия субъекта: волевой фактор, возможность осознать последствия своих действий, способность осуществлять выбор, наличие желания достичь определенный результат, цель и мотив таких действий. Иными словами, наличие каких факторов критично для того, чтобы оценить, насколько субъект дееспособен.

Попытка квалификации как всех субъективных элементов, так и его части в каждом правоотношении приведет к правовому коллапсу, поскольку вместо установление содержания правоотношения суды будут определять наличие способности у стороны действовать в целях создания юридических прав и обязанностей. Для исключения такого развития событий законодатель идет по пути юридической фикции и презюмируют, что все физические лица становятся дееспособными при достижении определенного возраста. При том очевидно, что к определенному возрасту все подходят с разным уровнем осознанности и правосознания. Но понимание невозможности принять во внимание все индивидуальные особенности физического лица привело к правовому обобщению и действию метода исключения, когда доказывать следует отклонение от общей нормы.

В соответствии с Гражданским Кодексом РФ лицо становится полностью дееспособным с достижением совершеннолетия - т.е. восемнадцатилетия. По- ложения статьи 21 ГК РФ исходят из того, что полная дееспособность может наступить до 18 лет в случае заключения брака, если такая возможность предусмотрена семейным законодательством. Здесь снова сталкиваемся с юридическим допущением, о том, что лицо, вступившее в брак до 18 лет, уже сознательно и имеет возможность давать отчет своим действиям несмотря на то, что это предположение вряд ли имеет связь с реальной жизнью. Возможность юридической активности обусловлена необходимостью вести семейный образ жизни, который активизирует различные гражданско-правовые институты, чтобы не заниматься частичным предоставлением прав, закон признает лиц полностью дееспособными.

Другое исключение из общего правила о дееспособности совершеннолетних лиц, связано с тем, что правоотношения иерархичны, с точки зрения, сложности их реализации и понимания. Для того чтобы быть участником определенных отношений необходимы знания и профессиональный опыт (например заключение договора франчайзинга или покупки фьючерсов), другие носят бытовой характер, они просты в исполнении и при их реализации достигается понятный и очевидный результат (например покупка товара в магазине). Наличие такой внутренней структуры стало причиной появления отдельного понятия дееспособности несовершеннолетних в возрасте от 14 до 18 лет (ст. 26 ГК РФ). Правоотношения, в которые может вступать указанная категория лиц, никак не связаны с анализом их психологической способности своими действиями создавать для себя права и обязанности, они обусловлены исключительно простотой договорных связей. К таким правоотношениям, например, относятся мелкие бытовые сделки, распоряжение своим заработком, осуществление прав автора и т.д.

Еще одним исключением из общего правила о дееспособности является процедура эмансипации[9], которая в отличие от частичной дееспособности несовершеннолетних от 14 до 18 лет, строится на персональных особенностях лица, достигшего 16 лет. Так лицо, которое осуществляет трудовую деятельность или с согласия родителей занимается предпринимательской деятельностью может быть признано полностью дееспособным по заявлению родителей органами опеки и попечительства. При этой процедуре происходит оценка индивидуальных «способностей» субъекта своими действиями создавать себя права и нести обязанности в полном объеме, понимать значение своих действий и все возможные последствия [10].

Таким образом, законодательство РФ использует следующие подходы в отношении субъективного элемента участников правоотношений: 
- Правоспособность строится на базе пассивного обладания правами, для которого учет субъективного элемента не важен. Пассивность не предполагает волевых действий, а значит не требует оценки индивидуальных особенностей лица.

- Дееспособность предполагает, что лицо способно активно действовать и вступать в правоотношения с пониманием сути правоотношения и его правовых последствий. Субъективный фактор, определяющий способность к действию, является ключевым при принятии решения о дееспособности лица. Однако, индивидуальный подход ко всеми субъектам правоотношений невозможен, поэтому правовое регулирование идет по модели упрощенного допущения: все лица, достигшие 18 лет способны своими действиями создавать для себя права и нести обязанности.

Исключения возможны либо в случае «простоты» правоотношения, понять смысл, которого возможно и лицам, не достигнувшим совершеннолетия, либо индивидуальные особенности лица, настолько вовлеченного в гражданско-правовые отношения, что в рамках правового регулирования легче признать его дееспособным чем разделять ответственности между субъектом и его законными представителями. При этом процедура эмансипации представляет собой сложный правовой механизм, что исключает ее массовый характер.

Система общего права не дифференцирует понятия право и дееспособности и руководствуется предоставлением частичной дееспособности несовершеннолетним лицам. По общему правилу несовершеннолетние не могут быть связаны обязательствами, возникшими до восемнадцатилетия за исключением трех случаев. Первое исключение - возможность вступать в договорные отношение предметом которого являются товары первой необходимости. Такие предметы определены несколькими нормативными актами, включая Закон о продаже товаров (п.s 3(3))(Sale of Goods Act 1979 https://www.legislation.gov.uk/ukpga/1979/54), который в качестве таковых рассматривает товары, соответствующие условиям жизни несовершеннолетнего и его фактическим потребностям на момент поставки. Общее право еще шире толкует понятие товаров первой необходимости, так еще в решении 1840 года по делу Peters v. Fleming (1840 6M\&W42) кольца, брошь и часы были признаны предметами первой необходимости для несовершеннолетнего сына богатого отца. По сути, это означает, что несмотря на положение нормы, суд будет исходить из фактических потребностей несовершеннолетнего на момент заключения договора. В деле Nash v Inman (1908) 2 КВ1 суд посчитал что контракт на покупку 11 жилетов несовершеннолетним студентом Кембриджа не может считаться действительным поскольку такое количество вряд ли можно рассматривать как первую необходимость.

Вторым исключением является возможность своими действиями приобретать права и обязанности по трудовому договору, если контракт заключается в интересах несовершеннолетнего. Здесь важным является объект договорного регулирования, поскольку к этому исключению относится только трудовые соглашения или соглашения о предоставлении исключительных прав на публикацию работ несовершеннолетнего, сам факт интереса или выгоды несовершеннолетнего не является детерминирующим фактором.

Третье исключение связано с предоставлением «особого» статуса некоторыми контрактам, заключенных несовершеннолетними: такие сделки могут быть признаны оспоримыми, поскольку недействительной такую сделку может признать несовершеннолетний до момента достижения совершеннолетия. Здесь речь идет о длящихся правах, которые вытекают из определённых контрактов - например права, связанные с владением землей или акциями, а также участие в совместном предприятии. Логика правового регулирования проста - лицо, которое заключает договор с несовершеннолетним, осознает риски такой сделки для себя, потому не может рассчитывать на полноценное встречное исполнение, в то время как несовершеннолетний может не в полной мере осознавать последствия вступления в такие правоотношения. Если по достижению совершеннолетнего возраста контракт так и не будет оспорен лицом, то оно считается связанным соответствующими обязательствами без каких-либо ограничений.

Такие частичные изъятия из общего правила о дееспособности, противоречивая практика по вопросу признания дееспособности за несовершеннолетними в конкретных случаях привели к принятию закона контрактах, заключаемых несовершеннолетними (Minors' Contracts Act 1987, CHAPTER13 https://www.legislation. gov.uk/ukpga/1987/13?timeline=false). Основной задачей закона является реализация прав на имущество, полученное несовершеннолетним и иные права, которое были им получены и одобрены в последующем. При это многие авторы [11] отмечают негативный характер таких исключений по причине того, что в случае наличия недобросовестности и преднамеренного введения в заблуждения относительно своего возраста контрагенту несовершеннолетнего недоступны средства правовой защиты, которые носят договорной характер, поскольку это провоцирует вопрос о действительности контракта, заключаемого несовершеннолетним, и, следовательно, разрушает общие подходы к дееспособности. 
Следует еще раз отметить, что система общего права не выделает правоспособность и дееспособность, как самостоятельные категории, законы, регулирующие вопросы относительно участия несовершеннолетних в различных правоотношениях по сути создают правовой режим схожий с правоспособностью и отвечают на вопрос, что делать с правами, которые возникают у лица, в том числе помимо его воли.

Большинство национальных правопорядков исходит из того, что некоторые лица в силу психологических особенностей или заболеваний могут утратить способность контролировать свои поступки или осознавать значение своих действий, иными словами, даже если лицо не утрачивает возможность совершать активные действия, они имеют явный волевой или психологический порок. Для таких случаев существует механизм признания лица недееспособным в противовес тому, что в соответствии с законом лицо является дееспособным. Задача данной процедуры исключить их гражданского оборота лиц, создающих неоднозначные правовые ситуации с непредсказуемым результатом. В таких случаях в гражданский оборот вступают поручители и опекуны, действующие в интересах недееспособного. Поскольку признание лица недееспособным важный юридический факт, он требует специальной процедуры и подтверждения. В соответствие со ст. 29 ГК РФ такое решение должно быть принято судом в рамках специальной процедуры

В странах общего права, например в Великобритании, существуют отдельные нормативно правовые акты, регулирующие психическое здоровье граждан (например, Mental Health Act 1983 https://www. legislation.gov.uk/ukpga/1979/54) которые регулируют различные варианты правовых последствий вследствие наличия у лица психического расстройства. В большинстве случаев суды не лишают лицо дееспособности в полном объеме, но определяют критически важный объем имущества субъекта, в отношении которого суд устанавливает особый контроль. С момента введения процедуры контроля отчуждение имущества или иное его обременение невозможно без соответствующего судебного приказа или решения уполномоченных лиц. При этом контрагент не освобождается от своих обязательств, вступая в сделку предметом которого является указанное имущество (дело Re Walker (1905) 1 СН 60). В случае если контроль суда за имуществом не установлен, то психическое расстройство само по себе не является основанием для расторжения контракта, за исключением случаев, когда факт недееспособности известен другой стороне. Однако, не все психологические случаи вызывающе очевидны, поэтому перенос бремени знаний на контрагента не всегда обоснован [12].
Пьянство, по сути, также относится к психическим расстройствам, если оно мешает понять значение своих действий, и другая сторона знает о его ситуационной недееспособности, то договор может быть отменен (Gore v Gibson (1843) 13 M\&W 623).

Таким образом, национальные правопорядки пытаются защитить лицо, которое в силу заболевания не может соответствовать критериям дееспособного человека, однако в большинстве случаев государства на идут по пути полного исключения субъекта из всех правоотношений, задача регулятора - выявить критичность транзакции для такого лица и лишить ее в случае необходимости юридической силы. Следует констатировать, что такой подход с точки зрения правоприменения и практики более сложный чем разовое признание лица недееспособным с его последующим исключением из частноправового оборота.

Отдельного внимания заслуживает вопрос правоспособности юридических лиц, как субъектов права, существование которых обусловлено правовой фикцией.

В системе общего права компании представляют собой лица, которые отделены от их владельцев. Но при этом их правоспособность ограничена теми целями ради которой они создаются и которые содержатся в ее учредительных документах. Если компаниями действует не в соответствии со своими целями, то она действует ultra vires (с превышением полномочий) и можно сказать, что действует за пределами своей правоспособности. Так в деле Ashbury Railway Carriage and Iron Co v Riche (1875) LR7 HL 653). Было отмечено, что контракт заключенные с превышением полномочий был недействительным. Многие ученые полагают, что единственной причиной существования принципа ultra vires является защита акционера от действий, когда их деньги используются не в их интересах (Cotman v Brougham (1918) AC514, 540). На практике это также обеспечивает защиту тех, кто предоставляет денежные средства компании, поскольку по учредительным документам они могли сделать вывод о целях, куда данные денежные средства будут направленными. Здесь действует схожий механизм с целевым кредитом - когда цели, ради реализации которых денежные средства предоставляются, имеют существенное значение. С другой стороны, защита интересов акционером сталкивается с правами третьих лиц, которые могут не знать о существовании ограничений и вступили в правоотношения с юридическим лицом полагаю, что оно действует в пределах своих полномочий. Поэтому развитие судебной практики логично развивалось в сторону создания исключений, которые бы защищали невиновную третью сторону, действующую добросовестно при вступлении в правоотношения с компанией. С учетом наработанной су- 
дебной практики соответствующие исключения нашли отражения в Законе о компаниях 1985 (Companies Act 1985 год https://www.legislation.gov.uk/ukpga/1985/6/ contents), так в ст 35(1) прямо предусмотрено, что юридическая сила действия, совершенного компанией, не должна ставиться под сомнение на основании отсутствия полномочий по причине того, что она выходит за пределы целей компании, указанных в учредительном договоре.

Цель данных положений - вывести принцип ultra vires из взаимоотношений с добросовестной третьей стороной и переместить его на уровень отношений между акционерами и компанией (по сути, между исполнительным органом компании), что делает ultra vires подходом используемым для внутренних, а не для внешних целей.

Зависимость правоспособности от цели существует и в российском гражданском праве, однако содержательно это имеет значение только в рамках деления юридических на некоммерческие и коммерческие. Детализация целей обычно существует в учредитель- ных документах, однако перечень практически всегда носит открытый характер и общество может преследовать иные предпринимательские цели. Статья 49 ГК РФ также закрепляет данный подход и приравнивает правоспособность юридических лиц к возможности осуществлять любую деятельность незапрещенную законом. Исключением из общего правила является специальная деятельность, для которой необходимо получение лицензии.

Резюмируя следует отметить, что дееспособность первый этап на котором происходит анализ и квалификация субъективной составляющей правоотношения лицо должно пройти проверку на возможность быть участником правоотношений. Далее правоотношения могут развиваться в различных направлениях и судебные инстанции неоднократно прибегают к квалификации личностного восприятия юридически значимых действий субъектами. Принцип правовой определенности требует от всех лиц, влияющих на правоотношение понятной оценки всех ключевых элементов, которые могут изменить, прекратить и иным образом воспрепятствовать достижению правового результата.

\section{ЛИТЕРАТУРА}

1. Pavlakos, G. (2011) Law, normativity and the model of norms. In: Bertea, S. and Pavlakos, G. (eds.) New Essays on the Normativity of Law. Series: Law and practical reason (3). Hart Publishing, 0xford, pp. 246-280. ISBN978-1849462389

2. Sylvie Delacroix, "Understanding normativity", Revus, $37 \mid 2019,17-28$.

3. D. Plunkett, S. Shapiro, K. Toh, Dimensions of Normativity: New Essays on Metaethics and Jurisprudence. Oxford University Press, 2019.

4. Péter Cserne, Discourses on Judicial Formalism in Central and Eastern Europe: Symptom of an Inferiority Complex?, European Review, 10.1017/ S1062798720000320, (1-12), (2020).

5. Hart, H.L.A. 1994. The Concept of Law. With a postscript edited by P.A. Bulloch and J. Raz. 2nd ed. Oxford: Clarendon. (1st ed. 1961.)

6. Antonov, M. (2020). "Introduction". In Formalism, Decisionism and Conservatism in Russian Law. Leiden, The Netherlands: Brill | Nijhoff. doi: https://doi. org/10.1163/9789004442580_002

7. Belete, M. (2019) The "Principle of Autonomy" in Contract under the Civil Code of Ethiopian: Is It an Absolute Principle?. Beijing Law Review, 10, 795-805. doi: 10.4236/blr.2019.104043.

8. Малахов Валерий Петрович Сущность правоспособности человека // Пространство и Время. 2015. № 1-2 (19-20). URL: https://cyberleninka.ru/ article/n/suschnost-pravosposobnosti-cheloveka (дата обращения: 19.11.2021).

9. Белозерцева Виктория Владимировна. «Эмансипация несовершеннолетних лиц по российскому гражданскому праву» Социально-политические науки, по. 5, 2018, рр. 197-200.

10. Букшина Светлана Владимировна. «Правосубъектность несовершеннолетних: необходимость реформирования гражданского законодательства» Актуальные проблемы российского права, N. 5, 2015, стр. 64-68.

11. Burrows "The Law of Restitution" (second edition) Butterworths, 2002, p. 560-561

12. Hudson «Mental Incapacity Revisited», The Conveyancer and Property Lawyer, 1986, p. 178

( ) Зайцева Наталья Викторовна ( zaytsevanv@gmail.com ).

Журнал «Современная наука: актуальные проблемы теории и практики» 